\title{
EFEKTIVITAS ABDOMNAL STRETCHING EXERCISE DAN SENAM DISMNIOREA TERHADAP PENURUNAN NYERI DISMINOREA PRIMER
}

The Effectiveness Of Abdomnal Stretching Exercise And Dysmniorea Exercise To Reduce Primary Dysminorea Pain

\author{
Taqiyatun ${ }^{1}$, Kholisotin², Zainal Munir3 ${ }^{3}$, Ahmad Kholid4 \\ Fakultas Kesehatan Prodi Studi S1 Keperawatan Universitas Nurul Jadid Paiton Probolinggo \\ Email: taqyatemde@gmail.com
}

\begin{abstract}
Dysmenorrhea is pain that a woman experiences during menstruation. One of the treatments is abdominal stretching exercise and dysmenorrhea gymnastics. This study aims to determine the effectiveness of abdominal stretching exercises and dysmenorrhea gymnastics on reducing primary dysmenorrhea pain in young women at Darul Lughah Wal Karomah Kraksaan Islamic boarding school, Probolinggo. The research design used Pre Experimental Design with two groups pretest-posttest design. The sample was taken with cluster random sampling so that the sample of 70 respondents experienced dysmenorrhea. The results of the study using the paired-sample t-test in the abdominal stretching exercise group obtained a $P$-value of 0.000 , the dysmenorrhea group had a $P$ value of 0.000 and the combination group of abdominal stretching exercise and dysmenorrhea had a P-value of 0.83. Conclusion: shows a significant effect before and after the intervention. The comparison between these three groups shows that abdominal stretching exercise and dysmenorrhea gymnastics are equally effective in reducing the pain intensity of primary dysmenorrhea in adolescent girls. Whereas in the group, the combination of abdominal stretching exercise and dysmenorrhea gymnastics was not recommended as an intervention to reduce primary dysmenorrhea pain, because it could cause other pain. Such as knee pain, low back pain, fatigue and the risk of injury to other physical parts.
\end{abstract}

Keywords: abdominal stretching exercise, Dysmenorrhea, Dysmenorrhea gymnastics, Menstruation,.

\section{Abstrak}

Disminorea merupakan nyeri yang di alami seorang wanita saat menstruasi. Salah satu penanganannya adalah dengan abdominal stretching exercise dan senam disminorea, Penelitian ini bertujuan untuk mengetahui Efektifitas Abdominal Stretching Exercise Dan Senam Disminorea Terhadap Penurunan Nyeri Disminorea Primer Pada Remaja Putri Di Pondok Pesantren Darul Lughah Wal Karomah Kraksaan Probolinggo. Desain penelitian ini menggunakan Pre Eksperimental Design dengan two group pretest-posttest design Pengambilan sampel dengan cluster random sampling, sehingga sampel sebanyak 70 responden yang mengalami disminorea. Hasil penelitian menggunakan paired sample $t$ test pada kelompok abdominal stretching exercise di peroleh nilai hasil $\mathrm{P}$ value 0,000 , pada kelompok senam disminorea di peroleh nilai hasil $P$ value 0,000 dan pada kelompok perpaduan abdominal stretching execise dan senam disminorea di peroleh nilai hasil $P$ value 0,83 . Kesimpulan: menunjukkan adanya pengaruh yang signifikan sebelum dan sesudah di berikan intervensi. perbandingan antara ketiga klompok ini menunjukkan bahwa abdominal stretching exercise dan senam disminorea sama sama efektif untuk menurunkan intensitas nyeri disminorea primer pada remaja putri. Sedangkan pada kelompok perpaduan intervensi abdominal stretching exercise dan senam disminorea tidak di rekomendasikan menjadi intervensi mengurangi nyeri disminorea primer, di karenakan bisa menimbulkan nyeri yang lain. Seperti nyeri lutut, nyeri pinggang, kelelahan dan resiko cedera bagian fisik lainnya.

Kata Kunci : abdominal stretching exercise, Disminorea, Senam disminorea.

\section{PENDAHULUAN}

Masa remaja adalah di mulai dari usia 12 sampai usia 23 tahun yang di anggap masa topan badai dan stress, masa perkembangan yang dinamis biasanya di tandai dengan beberapa perubahan di antaranya perkembangan fisik kognetif sosial dan emosional yang begitu cepat, perubahan yang paling awal pada remaja yaitu perkembangan fisik atau biologis salah satunya remaja akan mengalami menstruasi atau haid (Pereda, 2015). Menstruasi merupakan pertanda masa produktif pada kehidupan seorang wanita yang di mulai dari menarke (haid pertama) sampai terjadinya menopause (berhentinya masa haid) (Rahmawati, 2016). Disminorea merupakam masalah genetik yang umum yang biasanya di tandai dengan rasa nyeri di bagian perut dan pinggang dalam beberapa hari pertama dari siklus 
menstruasi, yang membatasi aktivitas sehari hari wanita. Hal ini di bagi menjadi dua klompok yaitu disminorea primer dan disminorea sekunder (Sahin, 2018).

Menurut data dari world health organization (WHO) di dapatkan kejadian sebesar 1.769.425 jiwa $(90 \%)$ wanita yang mengalami disminorea dengan (10 15\%) mengalami disminorea berat (Ratnasari, 2018). Angka kejadian nyeri menstruasi (disminorea) di indonesia sebesar $64,25 \%$ yang terjadi dari $54,89 \%$ disminorea primer dan $9,36 \%$ disminorea sekunder (Pereda, 2015). Di jawa timur jumlah remaja putri yang berusia 10 - 24 tahun adalah sebesar 56.589 jiwa, dan yang mengalami disminorea sebesar 11.565 jiwa (Saadah, Setyarini, \& Mardiyanti, 2017). Berdasarkan hasil studi pendahuluan yang di lakukan pada tanggal 09 Oktober 2019 di Wilayah Pondok Pesantren Darul Lughah Wal karomah Karaksaan Probolinggo hasil dari wawancara lansung kepada ketua poskestren dan beberapa santri yang mengalami disminorea primer sejumlah 337 santri dengan jumlah santri 650 santri. Nyeri yang mereka alami bervariasi yaitu di antaranya kram perut, nyeri pada pinggang, mual, muntah, dan bahkan ada yang pingsan.

Disminore memberikan dampak negatif terhadap kualitas hidup perempuan yang terkena dampak, seperti mempengaruhi kinerja akademik dan kegiatan social (Helwa, 2018). Beberapa terapi yang dapat dilakukan untuk mengurangi intensitas nyeri, baik terapi farmakologis maupun terapi non farmakologis. Secara farmakologis nyeri bisa ditangani dengan terapi analgesik yang termasuk metode paling umum di gunakan untuk menghilangkan nyeri, akan tetapi terapi ini dapat berdampak ketagihan dan akan memberikan efek samping obat yang berbahaya bagi pasien (Fikriyah, 2017). Manajemen non farmakologi yang bisa di lakukan antara lain kompres hangat, teknik relaksasi, distraksi, yoga, exercise, olahraga dan senam secara teratur (Nikmatul, 2018). Dalam hal ini perlu adanya alternatif lain yang mudah untuk mencegah atau mungkin bisa mengurangi angka kejadian disminorea di antaranya adalah melakukan terapi abdominal stretching exercise Dan melakukan senam disminorea (Purwaningsih, 2013). Abdominal stretching exercise akan mengaktifkan kelenjar petiutari yang bisa memberikan perasaan senang dan daya tahan terhadap perasaan nyeri, kelenjar petiutari akan menstimulus hormon endorphin sehingga memberikan rasa senang terhadap individu tersebut (Setyorini, 2018). Sajalan dengan penelitian yang dilakukan sebelumnya Abdominal stretching exercise ini di lakukan 2 - 3 kali dalam satu minggu dengan durasi waktu 10 - 15 menit (Windastiwi, 2017).

Senam disminorea merupakan senam yang dapat membantu peregangan seputar otot perut, panggul dan pinggang, selain itu senam disminorea dapat memberikan perasaan nyaman yang berangsur angsur dilakukan secara teratur. Manfaat senam disminorea yaitu membantu mengurangi rasa nyeri terhadap wanita yang sedang mengalami disminorea (Nurjanah, 2019). Senam disminorea dapat dilakukan 3-5 kali dalam satu minggu dengan durasi waktu 30 menit (Sulistiyoningrum, 2018).

Berdasarkan permasalahan di atas peneliti tertarik untuk melakukan penelitian tentang "Efektifitas terapi abdominal stretching exercise dan senam disminorea terhadap penurunan intensitas nyeri disminorea primer pada remaja putri di pondok pesantren darul lughah wal karomah"

\section{METODE PENELITIAN}

Desain penelitian yang digunakan dalam penelitian ini adalah Pre Eksperimental Design dengan two group pretest-posttest design, yaitu penelitian melibatkan dua kelompok subjek. Kelompok subjek pertama dan kelompok subjek ke dua di lakukan observasi sebelum dan setelah di lakukan intervensi (Nursalam, 2017). Dalam penelitian ini sampling yang di gunakan adalah cluster random sampling dengan jumlah responden 70 santri.Teknik analisis data menggunakan uji $T$ berpasangan (uji paired t-test) dan uji $\mathrm{T}$ tidak berpasangan (Independent T-Test) (Indra, 2019).

\section{HASIL PENELITIAN}

1. Analisis univariat

a. Data Skala nyeri pada siswi yang mengalami diminorea primer Pada Kelompok intervensi (abdominal stretching exercise) 
Tabel 1: Skala Nyeri Siswi sebelum dan Sesudah Intervensi Siswi pada Kelompok Intervensi (Abdominal Stretsching Exercise)

\begin{tabular}{|c|c|c|c|c|c|}
\hline \multirow[t]{2}{*}{ No } & \multirow[t]{2}{*}{ Skala nyeri } & \multicolumn{2}{|c|}{$\begin{array}{l}\text { Sebelum } \\
\text { intervensi }\end{array}$} & \multicolumn{2}{|c|}{ Sesudah intervensi } \\
\hline & & $F$ & $\%$ & $\mathrm{~F}$ & $\%$ \\
\hline 1 & $\begin{array}{c}\text { Tidak ada } \\
\text { nyeri }\end{array}$ & - & - & 8 & $32 \%$ \\
\hline 2 & Ringan & 4 & $16 \%$ & 17 & $68 \%$ \\
\hline \multirow[t]{2}{*}{3} & Sedang & 21 & $84 \%$ & - & - \\
\hline & Jumlah & 25 & $100 \%$ & 25 & $100 \%$ \\
\hline
\end{tabular}

Berdasarkan table 1 sebelum dilakukan abdominal stretching exercise terdapat 4 responden (16\%) dengan responden (32\%) berada pada skala nyeri tidak ada nyeri, skala nyeri ringan, 21 responden $(84 \%)$ dengan skala nyeri sedang, dan setelah dilakukan abdominal stretching exercise terjadi penurunan skala nyeri yaitu terdapat 8

17 responden $(68 \%)$ dengan skala nyeri ringan.

b. Data Skala nyeri pada siswi yang mengalami diminorea primer Pada Kelompok intervensi (Senam Disminorea)

Tabel 2: Skala Nyeri Siswi Sebelum dan Sesudah Intervensi pada Kelompok Intervensi (Senam Disminorea)

\begin{tabular}{cccccc}
\hline \multirow{2}{*}{ No } & \multirow{2}{*}{ Skala nyeri } & \multicolumn{2}{c}{ Sebelum intervensi } & \multicolumn{2}{c}{ Sesudah intervensi } \\
\cline { 2 - 6 } & F & $\%$ & $\mathbf{F}$ & $\%$ \\
\hline 1 & Tidak ada nyeri & - & - & 5 & $20 \%$ \\
2 & Ringan & 6 & $24 \%$ & 20 & $80 \%$ \\
3 & Sedang & 19 & $76 \%$ & - & - \\
\hline & Jumlah & $\mathbf{2 5}$ & $\mathbf{1 0 0 \%}$ & $\mathbf{2 5}$ & $\mathbf{1 0 0 \%}$ \\
\hline
\end{tabular}

Berdasarkan tabel 2 sebelum dilakukan senam disminorea terdapat 6 responden $(24 \%)$ dengan skala nyeri ringan, 19 responden $(76 \%)$ dengan skala nyeri sedang, dan setelah dilakukan senam disminorea terjadi penurunan skala nyeri yaitu terdapat 5 responden $(20 \%)$

berada pada skala nyeri tidak ada nyeri, 20 responden (80\%) dengan skala nyeri ringan.

c. Data Skala nyeri pada siswi yang mengalami diminorea primer Pada Kelompok intervensi (abdominal stretching exercise dan senam disminorea)

Tabel 3: Skala Nyeri Siswi Sebelum dan Sesudah Intervensi pada Kelompok Intervensi (abdominal stretching exercise dan senam disminorea)

\begin{tabular}{cccccc}
\hline \multirow{2}{*}{ No } & Skala nyeri & \multicolumn{2}{c}{ Sebelum intervensi } & \multicolumn{2}{c}{ Sesudah intervensi } \\
\cline { 3 - 6 } & & $\mathbf{F}$ & $\%$ & $\mathbf{F}$ & $\%$ \\
\hline 1 & Tidak ada nyeri & & - & - & - \\
2 & Ringan & 1 & $5 \%$ & 1 & $5 \%$ \\
3 & Sedang & 19 & $95 \%$ & 19 & $95 \%$ \\
& Jumlah & $\mathbf{2 0}$ & $\mathbf{1 0 0 \%}$ & $\mathbf{2 0}$ & $\mathbf{1 0 0 \%}$ \\
\hline
\end{tabular}

Berdasarkan tabel 3 sebelum dilakukan perpaduan antara abdominal stretching exercise dan senam disminorea terdapat 1 responden (5\%) dengan skala nyeri ringan, 19 responden $(95 \%)$ dengan skala nyeri sedang, dan setelah dilakukan perpaduan antara abdominal stretching exercise dan senam disminorea terjadi penurunan skala nyeri yaitu terdapat 1 responden (5\%) berada pada skala nyeri ringan, 19 responden (95\%) dengan skala nyeri senang.

\section{Analisa bivariat}

Perbandingan Nilai nyeri disminorea Pada Kelompok intervensi (abdominal stretching exercise), (senam disminore) dan kelompok perpaduan intervensi (senam disminorea dan abdominal stretching exercise). 
Tabel 4: Perbandingan Nilai nyeri disminorea Pada Kelompok intervensi (abdominal stretching exercise), (senam disminore) dan kelompok perpaduan intervensi (senam disminorea dan abdominal stretching exercise).

\begin{tabular}{cccccc}
\hline Nyeri disminorea & Mean & SD & SE & $P$-value & N \\
\hline $\begin{array}{c}\text { Kelompok abdominal } \\
\text { stretching exercise }\end{array}$ & 1,4400 & 86217 & 17243 & & \\
$\begin{array}{c}\text { Kelompok senam } \\
\text { disminorea }\end{array}$ & 1,0800 & 1,00333 & 20067 & 0,000 & 50 \\
$\begin{array}{c}\text { Kelompok (abdominal } \\
\text { stretching exercise dan } \\
\text { senam disminorea) }\end{array}$ & 4.9000 & 852224 & 19057 & 0.83 & 20 \\
\hline
\end{tabular}

Berdasarkan tabel 4 didapatkan hasil uji statistik menggunakan Independent T-Test sebelum dilakukan senam disminorea pada kelompok intervensi abdominal stretching exercise dengan jumlah 25 responden, di dapatkan nilai rata-rata 1.4400 dengan standar deviasi 86217. Sedangkan pada kelompok senam disminorea dengan jumlah 25 responden, di dapatkan nilai rata rata 1,0800 dengan standart deviasi 1,00333. Sedangkan kelompok intervensi perpaduan abdominal stretching exercise dan senam disminorea dengan jumlah 20 responden didapatkan nilai rata-rata 4,9000 dengan standar deviasi 852224. Dari hasil uji statistik didapatkan nilai $P$-value $0,830(P<0,05)$ yang artinya ada perbedaan yang signifikan antara kelompok abdominal stretching exercise, kelompok senam disminorea, dan perpaduan antara abdominal stretching exercise dan senam disminore.

\section{PEMBAHASAN}

Menstruasi adalah siklus alami yang biasa terjadi pada wanita yang merupakan peluruhan lapisan Rahim yang terdiri dari darah dan terjadi setiap satu bulan satu kali, kecuali selama kehamilan (Ekawati, 2017). Disminorea adalah rasa nyeri saat menstruasi (Fransiska, 2018). Disminorea merupakan masalah genetik yang umum yang biasanya di tandai dengan rasa nyeri di bagian perut dan pinggang dalam beberapa hari pertama dari siklus menstruasi, yang membatasi aktivitas sehari hari wanita. Hal ini di bagi menjadi dua klompok yaitu disminorea primer dan disminorea sekunder (Sahin, 2018). Dalam hal ini perlu adanya alternatif lain yang mudah untuk mencegah atau mungkin bisa mengurangi angka kejadian disminorea di antaranya adalah melakukan abdominal stretching exercise (Hadisaputro, 2016).

Exercise merupakan salah satu manajemen non farmakologis yang lebih aman digunakan karena menggunakan proses fisiologis tubuh. Exercise merupakan salah satu teknik rileksasi yang dapat digunakan untuk mengurangi nyeri. Stretching atau peregangan adalah aktivitas fisik yang paling sederhana (Hadisaputro, 2016).
Abdominal stretching exercise adalah salah satu latihan yang sederhana, meningkatkan kebugaran, relaksasi fisik, meningkatkan perkembangan kesadaran tubuh, mengurangi ketegangan otot (kram), mengurangi nyeri otot dan mengurangi rasa sakit saat menstruasi (Setyorini, 2018). Selain itu abdominal stretching exercise untuk menurunkan intensitas nyeri disminorea, wanita yang mengalami disminorea di sarankan untuk melakukan abdominal stretching exercise ini, agar intensitas nyeri yang di rasakan saat disminorea dapat berkurang dan angka kejadian disminorea juga dapat menurun (Windastiwi, 2017).

Menurut hasil penelitian Mahvash yang telah di lakukan pada mahasiswi di iran di dapatkan hasill bahwa terdapat penurunan yang signifikan terhadap penurunan intensitas dan durasi nyeri disminorea setelah dilakukan aktivitas fisik tersebut $(p=0.01)$ (Mahvash, 2012). Saat melakukan abdominal stretching exercise akan menghasilkan hormon endorphin, endorfin memiliki struktur yang sama dengan morfin yaitu obat yang di gunakan untuk menghilangkan rasa sakit atau nyeri (Rokade, 2011).

Sedangkan hasil penelitian tarigan yang berjudul "Pengaruh Abdominal Stretching Exercise Terhadap Intensitas Nyeri Menstruasi (Dismenorea) Pada Remaja Putri”. Abdominal stretching exercise akan mengaktifkan kelenjar petiutari yang bisa memberikan perasaan senang dan daya tahan terhadap perasaan nyeri, kelenjar petiutari akan menstimulus hormon endorphin sehingga memberikan rasa senang terhadap individu tersebut. Hasil penelitian menyarankan remaja putri yang mengalami disminorea primer melakukan abdominal stretching exercise saat disminorea supaya tidak merasakan nyeri saat menstruasi (Tarigan, 2013).

Senam disminorea merupakan senam yang dapat membantu peregangan seputar otot perut, panggul dan pinggang, selain itu senam disminorea dapat memberikan perasaan nyaman yang berangsur angsur dilakukan secara teratur. Manfaat senam disminorea yaitu membantu mengurangi rasa nyeri terhadap wanita yang sedang mengalami disminorea (Nurjanah, 2019). Menurut 
Vol. 12 No. 012021

e-issn : 2622-0148, p-issn : 2087-0035

penelitian sebelumnya di sarankan agar pemberian terapi senam disminorea ini di jadikan sebagai intervensi alternatif untuk menurunkan nyeri haid dan hasil penelitian menunjukkan bahwa ada perbedaan yang signifikan sebelum dan sesudah di berikan intervensi senam disminorea dengan $p<0,001$ maka di simpulkan bahwa terdapat efektivitas terhadap intervensi senam disminorea (Sarifah, 2018).

Penelitian ini sejalan dengan penelitian yang dilakukan oleh Ica Solehatunisa menunjukkan Senam efektif untuk menurunkan intensitas nyeri saat dismenore. Maka disarankan bagi penderita dismenore untuk melakukan senam ini, agar skala nyeri saat dismenorea dapat berkurang dan angka kejadian dismenorea juga dapat menurun. Sedangkan menurut purwaningsih Senam merupakan salah satu tehnik relaksasi yang dapat digunakan untuk mengurangi nyeri pada saat menstruasi. Karena saat melakukan olahraga/senam otak dan susunan syaraf tulang belakang akan menghasilkan endorphin, hormon yang berfungsi sebagai obat penenang alami dan menimbulkan rasa nyaman (Solihatunisa, 2012).

Menurut penelitian Rofli Marlinda dengan berjudul "Pengaruh Senam Disminorea Terhadap Penurunan Disminorea Pada Remaja Putri di SMKN Jombang" Hasil penelitian dengan menggunakan uji nonparametrik Mann-Whitney menunjukkan $p$-value sebesar 0,000 dan hasil yang di dapatkan $p$-value $0,000<(0,05)$, maka ada pengaruh senam disminorea terhadap penurunan disminorea, sehingga senam disminorea dapat digunakan sebagai alternatif terapi non farmakologi untuk penatalaksanaan disminorea (Nuraeni, 2017).

Penelitian ini juga sejalan dengan penelitian yang di lakukan oleh sa'adah ummi dkk yang berjudul "The effect hatha yoga on dysminhorea pain in adolescent principle" yang di lakukan di Pondok Pesantren Darul Falah dengan jumlah 76 santri sebagai reponden dan hasil penelitian senam efektif untuk menurunkan skala nyeri disminorea primer pada remaja putri di Pondok Pesantren Darul Falah (Kholisotin, Ummi, \& Zainal, 2019).

Penelitian ini dukung oleh solihatunnisa' yang berjudul "Pengaruh Senam Terhadap Penurunan Intensitas Nyeri Saat Dismenore Pada Mahasiswi Program Studi Ilmu
Keperawatan UIN Syarif Hidayatullah Jakarta" yang menyatakan Frekuensi latihan terlalu banyak atau terlalu sering melakukan pergerakan senam dikhawatirkan beristirahat yang tidak cukup sehingga dapat menimbulkan sakit / over training. Over training adalah suatu kondisi adanya proses latihan yang berlebihan disertai dengan waktu pemulihan yang tidak cukup atau singkat, sehingga menyebabkan kelelahan (Solihatunisa, 2012).

Over training bisa menyebabkan kelelahan, ketegangan otot (kram), pegal otot dan ketegangan otot yang dapat menyebabkan rasa sakit (Subhan \& Graha, 2019). Apabila over training di biarkan maka akan terjadi cedera, cedera bisa menghambat aktivitas dan mobilitas fisik terhadap seseorang (M, Foye, M, Shah, \& Sinha, 2017). Oleh karna itu, perpaduan abdominal stretching exercise dan senam disminorea tidak di anjurkan dilakukan pada orang yang mengalami nyeri disminorea primer.

Menguatkan dari penelitian yang di lakukan oleh solihatunnisa' yang berjudul "Pengaruh Senam Terhadap Penurunan Intensitas Nyeri Saat Dismenore Pada Mahasiswi Program Studi IImu Keperawatan UIN Syarif Hidayatullah Jakarta" bahwa setelah peneliti melakukan penelitian di pondok pesantren darullughah wal karomah kraksaan probolinggo, perpaduan abdominal stretching exercise dan senam disminorea bisa mengurangi nyeri akan tetapi bisa menimbulkan nyeri yang lain. Seperti nyeri lutut, nyeri pinggang, kelelahan dan resiko cedera bagian fisik lainnya.

\section{KESIMPULAN}

Adanya pengaruh yang signifikan sebelum dan sesudah di berikan intervensi. perbandingan antara ketiga klompok ini menunjukkan bahwa abdominal stretching exercise dan senam disminorea sama sama efektif untuk menurunkan intensitas nyeri disminorea primer pada remaja putri. Sedangkan pada kelompok perpaduan intervensi abdominal stretching exercise dan senam disminorea tidak di rekomendasikan menjadi intervensi mengurangi nyeri disminorea primer, di karenakan bisa menimbulkan nyeri yang lain. Seperti nyeri lutut, nyeri pinggang, kelelahan dan resiko cedera bagian fisik lainnya.

\section{DAFTAR PUSTAKA}

Ekawati, E. N. (2017). Asuhan Kebidanan Gangguan Reproduksi Pada Nn.Y Umur 21 Tahun Dengan Amenoroe Sekunder Di Rsu Assalam Gemolong Sragen KARYA TULIS ILMIAH. https://digilib.ukh.ac.id

Fikriyah, U. (2017). penerapan abdominal stretching exercise terhadap penurunan intensitas nyeri dysminhorea pada remaja putri di bpm hj nuryamah kutowinangun kabupaten kebumen. Jurnal Kesehatan Prima Nusantara Bukit tinggi Volume 9 No 2 Juli 2018. http://download.garuda.ristekdikti.go.id

Fransiska. (2018). Pengaruh Kompres Dingin Terhadap Penurunan Intensitas Nyeri Pada Wanita Yang Mengalami Dismenore Di Rayon Ikabe Tlogomas. 3, 153-163. Nursing news:jurnal ilmiah keperawatan e-ISSN: 2527-9823. 
https://publikasi.unitri.ac.id

Hadisaputro, E. (2016). Pengaruh Abdominal Stretching Exercise Terhadap Penurunan Kadar Prostaglandin Pada Dismenore Primer. 1-41. Internasional Repository (UNDIP-IR) http://eprints.undip.ac.id

Helwa, H. A. A. (2018). Prevalensi dismenore dan prediktor intensitas nyeri di antara mahasiswa perempuan Palestina. 1-11. http://eprints.poltekkesjogja.ac.id

Indra, M. (2019). cara mudah memahami metode penelitian. yogyakarta. UMM press: Malang

Kholisotin, Ummi, S., \& Zainal, M. (2019). The effect of hatha yoga on dysmenorrhoea pain in. 2(2), 144-153. Maternity Care And Reproduksi Health ISSN 2621-8992 http://www.mcrhjournal.or.id

M, P., Foye, M, J., Shah, \& Sinha, D. (2017). musculoskeletal sport and spine disorders (1st ed.; S. Khan \& R. xu Yinfei, Eds.). USA: springer.

Mahvash, N. (2012). The effect of physical activity on primary disminhorea of famale university students. word applied sciences journal 17 (10):1246-1252 httop://www.researchgate.net

Nikmatul, A. (2018). pengaruh abdomenal stretching terhadap perubahan nyeri dysminhorea primer pada remaja putri. 4(3), 119-123. JKM (jurnal kebidanan malahayati) http://ejurlmalahayati.ac.id

Nuraeni. (2017). Terhadap Penurunan Nyeri Pada Remaja Putri Smk 1 Tapango Kecamatan Tapango Kabupaten. Jurnal IImiah Bidan, 11(1).

Nurjanah, I. (2019). Nyeri menstruasi pada mahasiswi asrama stikes muhammadiyah palembang. 10(1). Syifa' Medika: Jurnal

Kedokteran Dan kesehatan. https://jurnal.um-palembang.ac.id

Nursalam. (2017). metodelogi penelitian ilmu keperawatan. jakarta: salemba medika.

Pereda, N. (2015). urkessia, Vol. VI, No. 1, November 2015 Efektivitas Paket Pereda Terhadap Intensitas Nyeri Dismenore pada Remaja di SMP Ni Wayan Kurnia Widyawati, dkk. Negeri 1 Simpur Kabupaten Hulu Sungai Selatan Tahun. (November). JKI (Jurnal Keperawatan Indonesia). http://jki.ac.id

Purwaningsih, P. (2013). pengaruh senam disminore terhadap penurunan disminore pada remaja putri di desa sidoharjo kecamatan pati. 1(2), 118-123. Jurnal Keperawatan Maternitas . Volume 1, No. 2, November 2013; 118-123 http://jurnal.unimus.ac.id.

Rahmawati, N. (2016). pengaruh pemberian abdominal stretching exercise terhadap tingkat nyeri disminorea pada siswi di smp n 30 semarang. karya ilmiah STIKES telegorejo Volume 6, http://ejournal.stikestelogorejo.ac.id

Ratnasari, N. N. (2018). Pengaruh pelvic rocking exercise terhadap nyeri the effect of pelvic rocking exercise toward primary dysmenorhea pain junior high school grade 8. 4(02), 48-55. Jurnal Bidan "Midwife Journal" Volume 4 No. 02, Juli 2018 pISSN 2477-3441 elSSN 2477-345X, https://media.neliti.com

Rokade, P. (2011). Release of endomorphin hormone and its effect on our body. bangkok: ICCEBS.

Saadah, A. A., Setyarini, D. I., \& Mardiyanti, T. (2017). Asam jawa. 3(2), 57-63. Jurnal Keperawatan Terapan (eJournal) 3 (2), 57-63,

Sahin, N. (2018). Penilaian tingkat kecemasan-depresi dan persepsi kualitas hidup pada remaja dengan dismenore. 1-7. Sari Pediatri, Vol. 15, No. 1, Juni 2013, https://saripediatri.org.

Sarifah. (2018). Efektifitas senam disminorea terhadap Penurunan Nyeri Haid pada Siswi Kelas X dan XI SMAN 14 Semarang, 1. karya ilmiah STIKES telegorejo Volume 4, http://ejournal.stikestelogorejo.ac.id

Setyorini, Y. (2018). Efektifitas senam dengan modul dalam mengurangi dismenore pada remaja sma di kota surakarta Yuyun Setyorini, Satino. 000, 110-114. Intereset: Jurnal IImu Kesehatan poltekkes kemenkes surakarta ISSN: 2252-5432 EISSN: 2579-6135, https://jurnalinterset.com

Solihatunisa, I. (2012). Pengaruh Senam Terhadap Penurunan Intensitas Nyeri Saat Dismenore Pada Mahasiswi Program Studi IImu Keperawatan UIN Syarif Hidayatullah Jakarta. http://repository.uinjkt.ac.id/dspace/handle/123456789/25532

Subhan, A., \& Graha, S. (2019). the Effectivity of Therapy Massage for Sport Injury Toward Heel and Muscle Tibialis Pain in 
Jurnal Media Keperawatan: Politeknik Kesehatan Makassar

Vol. 12 No. 012021

e-issn : 2622-0148, p-issn : 2087-0035

One. XVIII(2), 56-63. MEDIKORA, Vol. XVIII No. 2 Oktober 2019, Hal 56-63, https://journal.uny.ac.id/index.php/medikora

Sulistiyoningrum, I. (2018). pengaruh senam disminorea terhadap derajat nyeri haid. 53-61. https://jurnal.stikesmus.ac.id.

Tarigan, B. D. J. (2013). Pengaruh abdominal stretching exercise terhadap intensitas nyeri menstruasi ( dismenorea ) pada remaja putri. (110), 38-43. Jurnal Kesehatan Prima Nusantara Bukit tinggi Volume 9 No 2 Juli 2018. http://download.garuda.ristekdikti.go.id

Windastiwi, W. (2017). Pengaruh Abdominal Stretching Exercise Terhadap Intensitas Nyeri Dismenorea. Jurnal Kebidanan, 6(12), 17. https://doi.org/10.31983/jkb.v6i12.1909 